\title{
A Measure of Price Pressures
}

\author{
Laura E. Jackson, Kevin L. Kliesen, and Michael T. Owyang
}

The Federal Reserve devotes significant resources to forecasting key economic variables such as real gross domestic product growth, employment, and inflation. The outlook for these variables also matters a great deal to businesses and financial market participants. The authors present a factor-augmented Bayesian vector autoregressive forecasting model that significantly outperforms both a benchmark random walk model and a pure time-series model. They then use these factors in an ordered probit model to develop the probability distribution over a 12-month horizon. One distribution assesses the probability that inflation will exceed 2.5 percent over the next year; they term this probability a price pressure measure. This price pressure measure would provide policymakers and markets with a quantitative assessment of the probability that average inflation over the next 12 months will be higher than the Fed's long-term inflation target of 2 percent. (JEL C32, C35, E31)

Federal Reserve Bank of St. Louis Review, First Quarter 2015, 97(1), pp. 25-52.

$\mathbf{T}$ he Federal Reserve, like most central banks, devotes considerable economic resources to monitoring and analyzing large volumes of economic data. This effort, often termed "current analysis" by insiders, feeds directly into another, crucial aspect of central banking: forecasting key economic series such as real gross domestic product (GDP) growth, inflation, and employment. Forecasting the paths of key economic variables is an effort that flows directly from the Fed's congressionally mandated responsibility to (i) provide sufficient liquidity to achieve and maintain low inflation rates and (ii) promote maximum sustainable economic growth. This responsibility, which stems from the Federal Reserve Act and subsequent amendments, is often termed the Fed's dual mandate. Since the passage of the DoddFrank Wall Street Reform and Consumer Protection Act, the Fed has been handed a third monetary policy responsibility: financial stability.

In this analysis, we focus on the Fed's price stability mandate-specifically, in the context of forecasting inflation. Given its importance, Federal Reserve officials have historically been reluctant to attach an explicit definition of price stability—a rather ambiguous term that can

\footnotetext{
Laura E. Jackson will join the faculty in the department of economics at Bentley University as an assistant professor in July 2015. Kevin L. Kliesen and Michael T. Owyang are research officers and economists at the Federal Reserve Bank of St. Louis. The authors benefited from conversations with Neville Francis. Lowell Ricketts and E. Katarina Vermann provided research assistance.

() 2015, The Federal Reserve Bank of St. Louis. The views expressed in this article are those of the author(s) and do not necessarily reflect the views of the Federal Reserve System, the Board of Governors, or the regional Federal Reserve Banks. Articles may be reprinted, reproduced, published, distributed, displayed, and transmitted in their entirety if copyright notice, author name(s), and full citation are included. Abstracts, synopses, and other derivative works may be made only with prior written permission of the Federal Reserve Bank of St. Louis.
} 


\section{Jackson, Kliesen, Owyang}

mean different things to different people. That reluctance changed in January 2012, when the Federal Reserve defined price stability as a numerical inflation target-2 percent-over the medium term (Board of Governors of the Federal Reserve System, 2013):

The Federal Open Market Committee (FOMC) judges that inflation at the rate of 2 percent (as measured by the annual change in the price index for personal consumption expenditures, or PCE) is most consistent over the longer run with the Federal Reserve's mandate for price stability and maximum employment. Over time, a higher inflation rate would reduce the public's ability to make accurate longer-term economic and financial decisions. On the other hand, a lower inflation rate would be associated with an elevated probability of falling into deflation, which means prices and perhaps wages, on average, are fallinga phenomenon associated with very weak economic conditions. Having at least a small level of inflation makes it less likely that the economy will experience harmful deflation if economic conditions weaken. The FOMC implements monetary policy to help maintain an inflation rate of 2 percent over the medium term.

The Fed's inflation-targeting regime, which is similar to those of many other major central banks, thus requires the FOMC to forecast future inflation ("inflation over the medium term"). But in a large structural model such as the Board of Governors FRB/US model, the inflation process is modeled largely on the New Keynesian Phillips curve (NKPC) framework. In the NKPC model, current inflation depends on both current economic conditions-typically measured as the deviation between actual output and potential output or, equivalently, between the current unemployment rate and the natural rate of unemployment-and agents' expectations of future inflation. ${ }^{1}$ Previous shocks matter only to the extent that they influence current conditions or expectations of future inflation. The NKPC model thus marries the Keynesian view that there is a short-run trade-off between real output (or unemployment) and inflation (by means of some "sticky price" mechanism) and the neoclassical view that, in the long run, excess money growth only leads to higher inflation (money neutrality).

We take a different approach in our analysis. First, our framework uses a pure time-series model to forecast inflation. Simple time-series models have been shown to be as accurate as larger, more complex structural models - and the resource demands on the forecaster are significantly smaller. ${ }^{2}$ Our model is a Bayesian vector autoregressive (VAR) model augmented with a set of factors that summarize disaggregated price, employment, and interest rate data. The set of factors is derived from approximately 100 economic and financial data series, including well-known measures of inflation expectations. We find, consistent with the NKPC, that inflation expectations matter. We use standard forecast accuracy tests to test whether our dynamic factor model produces a more accurate forecast than a simple, naive forecasting model (random walk) and a benchmark time-series model that forecasts future inflation based solely on lags of previous inflation. Finally, we use our dynamic model to produce forecast probabilities. For example, policymakers usually want to know whether the probability that inflation over the next four or eight quarters will exceed the Fed's 2 percent inflation target is greater or less than the probability that it will fall short of 2 percent. ${ }^{3}$

In our second exercise, we consider an alternative experiment in which we forecast the probabilities that the inflation rate will be in the target zone, rise above the target zone, be positive but fall below the target zone, or fall below zero. To do this, we construct a static ordered probit model with the appropriate cutoffs for the inflation rate. The model is augmented with 
the same factors used for the linear model previously described. Finally, we aggregate the various horizons' forecasted probabilities that the inflation rate will rise above the target zone to form an index that measures price pressures.

In the next section, we summarize some of the previous work on inflation forecasting. Faust and Wright (2013, henceforth FW) provide an outstanding reference for the current line of thinking; we refer readers to their paper for details but provide a helicopter view of the extant literature. The following section contains our linear forecasting exercise: Our goal is to use a large number of data series to forecast inflation at various horizons. We then describe our alternative experiment: Our goal is not to forecast the level of the inflation rate but to determine the risk that the inflation rate will exceed the Fed's inflation target.

\section{SUMMARIZING THE EXTANT LITERATURE}

The problem of forecasting future inflation has been well studied. FW provide an extensive survey of the inflation-forecasting literature, and readers seeking a comprehensive overview of this literature are encouraged to read their paper. Here, we provide a cursory summary of FW, note their key findings, and supplement FW with additional literature where appropriate.

FW compare forecasts of inflation constructed from 16 different models popular in the literature. These include, but are not limited to, VARs; the integrated moving average $(1,1)$ [IMA(1,1)] model advocated by Stock and Watson (2007, henceforth SW); the Atkeson and Ohanian (2001, henceforth AO) random walk model; various Phillips curve models; a dynamic stochastic general equilibrium (DSGE) model; and factor models. As a robustness check, they examine whether any of these model-based forecasts are superior to three "real-time judgmental forecasts." The first two forecasts are measures of consensus among professional forecasters (e.g., the Philadelphia Fed's Survey of Professional Forecasters [SPF] or the Blue Chip survey). The third measure is the Greenbook forecasts, compiled by the Board of Governors staff; Greenbook forecasts are available to the public with a minimum five-year lag. ${ }^{4}$

In general, FW present four key findings from their forecasting model comparison exercise. First, judgmental forecasts are usually the most accurate across a variety of inflation measures and time horizons. Taken literally, this means that there is a forecasting equivalent of the law of large numbers at work: The average of a large group of forecasters is a close approximation to the actual (expected) value. Second, forecasts beyond one or two quarters should have some method for capturing long-run trends in inflation. This means that inflation has a long-run trend. Importantly, this long-run trend is dependent on actions by the monetary authority. Third, more shrinkage of information tends to produce better results. By shrinkage, FW mean that the best forecasts rely on a good starting point, such as a nowcast. ${ }^{5}$ This mechanism implies that there is value in current information when forecasting future inflation. The fourth principle, which is related to the third, is that the best forecasts have "heavy handed" priors about the local mean. The third and fourth principles are deemed boundary values. In the view of FW, the best forecast thus conditions on the starting point (a nowcast) and an ending point (such as the Fed's long-run inflation target). They term this a fixed "glide path" or "swoop path." 


\section{FORECASTING INFLATION}

In this section, we perform an exercise similar to that of FW but more limited in scope. Because we are not interested in reinventing the wheel, we compare only a few models, focusing instead on the effect of adding data to the model. We focus on direct forecasts, although a similar exercise could be performed for indirect forecasts. ${ }^{6}$ Each exercise is a quasi-out-ofsample evaluation of the forecasting performance of each model. We measure performance in this section the usual way, through the sum of the mean squared deviation of the forecast from its objective.

We sidestep two important issues. First, we do not use real-time data. Rudd and Whelan (2007) show how data revisions can significantly change the value of the initial parameters from a benchmark NKPC model originally estimated by Galí and Gertler (1999). Moreover, real-time measurement can be a significant issue for price series produced from national income accounts data, such as the PCE price index or the GDP price index. Second, we do not evaluate whether the forecasts are statistically significantly different from each other. The reason for our informality about these issues is that the following exercise has been essentially performed in FW, with only slight adjustments to the data. Here, we are simply interested in whether the addition of disaggregate price and wage measures improves the forecasting performance of the factor model. Aruoba and Diebold (2010), who use a Kalman filter framework to estimate an inflation index from six indicators, provide the closest antecedent to our approach. However, they do not use their index to forecast inflation. Instead, they view their inflation index as a coincident indicator to help policymakers or forecasters better determine whether inflation movements in real time are the product of demand- or supply-side shocks.

\section{The Models}

The objective is to forecast future inflation rates, $\pi_{t+h}$, using information available at time $t, \Omega_{t}$. We use three models in this section, each of which is increasingly dependent on the data. The first model, our baseline model for comparison, is the random walk forecast that AO claim works well:

$$
\hat{\pi}_{t+h \mid t}=\pi_{t-1}
$$

where $\hat{\pi}_{t+h \mid t}$ is the forecast of $\pi_{t+h}$ and $\pi_{t}$ is the current-period inflation rate. Here, inflation is solely a function of its own previous value. The random walk forecast takes advantage of the fact that trend inflation is persistent, but the short-term movements in inflation are transitory and difficult to predict. Second, we use a simple autoregressive model with lags of inflation, $A(L)$ :

$$
\hat{\pi}_{t+h \mid t}=A(L) \pi_{t}
$$

In a sense, this model nests the $\mathrm{AO}$ random walk specification but adds (potential) mean reversion. 
In the third model, we are interested in whether additional data can help forecast inflation at longer horizons. The conventional forecasting process of monetary policymakers typically uses structural models to obtain forecasts of a few key variables such as inflation, GDP, and the unemployment rate. These structural models often rely on theoretical restrictions and conditional policy paths. However, policymakers examine many other variables when making forecasts; for example, they may use these other data to judgmentally adjust the model-based forecasts. This process is known as ad-factoring the model to produce a forecast that, to a large extent, reflects the forecasters' or policymakers' biases. Thus, information about other economic indicators should, in principle, be useful in forecasting economic variables.

Our approach follows this framework but without the large structural model. A key problem is deciding which, if any, other series to include. One problem with using more data to construct the forecast is that the informational advantage of incorporating the additional data can be outweighed by the increased parameter uncertainty. Thus, more data do not always lead to better forecasts. This is particularly true for out-of-sample forecasting where the additional data lead to overfitting the in-sample fluctuations. Many empirical studies have shown that dynamic factor models (DFMs) may provide a parsimonious way to include incoming information about a wide variety of economic activity. These models use a large dataset to extract a few common factors. ${ }^{7}$ These factors are time-series variables such as inflation or employment growth. Many researchers have argued that DFMs can be used to improve empirical macroeconomic analysis and forecasting of key variables that inform the decisionmaking process of monetary policymakers. This DFM forecasting process has been termed a data-rich environment. $^{8}$

Using a large amount of data in the forecasting process has been popular with forecasters and policymakers for two reasons. First, important variables are likely to be omitted in smalldimension VARs. Effectively, this means that the more variables added to the model, the fewer degrees of freedom available to the forecaster. Second, the use of factor-augmented VARs (FAVARs) is consistent with the stochastic structure of a DSGE model, which is currently in vogue among many central banks. ${ }^{9}$ How so? Consider that at any point in time the economy is hit by numerous shocks, such as a surge in oil prices, a change in the tax environment, a collapse in asset prices, or a new technological innovation that significantly changes the production and distribution of a large swath of the nation's goods and services. These shocks affect the nation's key macroeconomic variables that matter to policymakers. DFMs, then, attempt to track the evolving equilibrium of these key variables, much as DSGE models are designed to do. ${ }^{10}$ We construct forecasts using a FAVAR to assess the effect of various data series. A factor is a method of summarizing information in a number of different kinds of series (e.g., commodity prices, employment series). The FAVAR is essentially a standard VAR augmented with a set of factors. Although the factors are intended to summarize large sets of data and prevent (or reduce) parameter proliferation, this does not necessarily imply there will not be overfitting in-sample.

We are interested in using a large number of (standardized) predictors summarized by the $N \times 1$ period- $t$ vector $\boldsymbol{X}_{t}$. The predictive content of a large vector of indicators can be condensed into a smaller set of $K$ factors, $\mathbf{F}_{t}$, where 


$$
\boldsymbol{X}_{t}=\Lambda \mathbf{F}_{t}+v_{t}
$$

where $\mathbf{F}_{t}$ is a period- $t(K \times 1)$ vector of factors, $K<<N$, $\Gamma$ is an $(N \times K)$ matrix of loadings, $v_{t} \sim N(0, \Omega)$, and $\Omega$ is diagonal. The diagonality assumption implies that the observed correlation across elements of the members of $\boldsymbol{X}_{t}$ is produced primarily by the factors. We can impose additional assumptions on the factor loadings to identify the factors. In particular, we assume that the loadings on some variables are zero; these zero restrictions are described later with the data.

The VAR that relates inflation, the other macro variables, and the factors is

$$
\left[\begin{array}{l}
\mathbf{y}_{t+h} \\
\mathbf{F}_{t+h}
\end{array}\right]=A(L)\left[\begin{array}{l}
\mathbf{y}_{t} \\
\mathbf{F}_{t}
\end{array}\right]+\varepsilon_{t+h},
$$

where $\mathbf{y}_{t}$ is a time- $t$ vector of macroeconomic series of interest (say, unemployment and inflation), $A(L)$ is a matrix polynomial in the lag operator, and $\boldsymbol{\varepsilon}_{t+h}$ is a vector multivariate normal innovation with zero mean and covariance matrix $\Sigma$. We construct the forecast of inflation from equation (4) by computing the expectation. In principle, equation (4) could include any number of additional variables; we suppress these for ease of exposition.

Equation (3) relates the factors to the large set of data that we want to summarize, and equation (4) relates the macroeconomic variables to lags of themselves and lags of the factors. Note that the contemporaneous factors do not inform the macroeconomic variables, and vice versa, except through the contemporaneous correlation in the error terms, which are assumed to be mean zero.

\section{Estimation, Forecasting, and Data}

The AO model requires no estimation because it is a random walk forecast. The autoregressive forecast is simply a standard autoregressive model with 12 lags of the dependent variable-either the 12-month percent change (logs) in the seasonally adjusted all-items consumer price index for all urban consumers (CPI-U) or the seasonally adjusted personal consumption expenditures chain-weighted price index (PCEPI). We estimate the factor model using Bayesian methods, conditioning on the factors generated using principal components. In generating the factors, we impose zero restrictions on the factor loadings described later.

The inflation rate is the object of interest, which we use two sets of data to predict. The first set of predictive data is the year-to-year percent change in the CPI or the PCEPI; these data enter into the VAR components of the models and include lags of the headline CPI or PCEPI inflation rate. The second set of data is used to construct the factors in the FAVAR; these data are listed in the appendix.

\section{The Factor Model Framework}

Table 1 condenses the data series from the appendix into the nine sets of predictive data that form the nine factors used in the FAVAR model. These data are composed of (1) consumer 


\section{Table 1}

\section{Types of Data Used in Factor Estimation}

Description

1. Consumer price indexes

2. Producer price indexes

3. Commodity prices

4. House and commercial property prices

5. Labor markets

6. Financial

7. Inflation expectations

8. Business and consumer surveys

9. Foreign prices

Total No. of series

NOTE: See the appendix for individual series, data transformations, and sources.
No. of individual series

23

7

12

6

11

14

17

6

8

104

price indexes, (2) producer price indexes, (3) commodity prices, (4) housing and commercial property prices, (5) labor market indicators, (6) financial variables, (7) inflation expectations, (8) survey data, and (9) foreign price variables. In choosing these variables, we wanted to focus first on monthly data of consumer and producer price indexes-the most obvious measure of price pressures. We also wanted to use series that measure prices in other dimensions, such as house and commercial property prices that influence rents. Similarly, we include certain commodity prices (e.g., crude oil prices) that affect the prices of goods and services consumed by consumers and producers.

From a broader standpoint, labor market variables have long been used by forecasters to help forecast inflation. According to the SPF, roughly two-thirds of survey participants incorporate some type of Phillips curve in their forecasting model. ${ }^{11}$ As noted earlier, expectations of financial and nonfinancial market participants (e.g., consumers and firms) underpin the New Keynesian model. Thus, financial market expectations and surveys of consumers and businesses represent about a quarter of our 104 variables. Finally, Neely and Rapach (2011), Ciccarelli and Mojon (2010), and others have documented that foreign prices strongly influence the U.S. domestic inflation rate. Thus, we include several foreign prices.

We estimate a single factor from each category, assuming that the factor for category $i$ does not load on variables in category $j$, equating to zero restrictions on the loadings. This approach allows for establishing a direct interpretation of the nature of each type of factor (e.g., summarizing consumer prices, producer prices, and so on). The alternative approach would be to extract a set of factors from the entire set of predictive variables. However, this makes it difficult to obtain a clear, definitive interpretation of which factor represents which source of inflationary pressures. We estimate the factors over two sample periods: February 1964-December 2013 and January 1983-December 2013. The latter period is sometimes referred to as the Great Moderation, which refers to the fact that the volatility of output, inflation, and many other 
macroeconomic time-series variables was much larger before 1983 than after $1983 .{ }^{12}$ We use a method for generating the principal components with unbalanced panels to estimate the factors. That is, the date of the first observation for all series is not the same; we then generate a separate factor for each subgroup determined earlier. This process yields an unbalanced panel of factors. Most factors begin in January 1964; the exception is the factor constructed using inflation expectations measures, the earliest of which (University of Michigan surveys of consumers) begins in January 1978. Finally, we perform two experiments. In the first experiment, we conduct out-of-sample forecast experiments using monthly revised data from the February 1964-December 2013 period. Here, we include eight different factors, excluding those related to inflation expectations. In the second experiment, we repeat the out-of-sample forecasts with data from the January 1983-December 2013 period and use a set of nine factors, now including the inflation expectations factor.

\section{Factor Loadings}

Tables 2 and 3 show the top three series in each category according to the magnitude of their loadings for the samples starting in 1964 and 1983, respectively. The loadings can provide insight because they reflect the correlation between each individual series and the factors: The greater the loading, the greater the correlations between the factor and the series in question. The factor model procedure produces an estimate of $\hat{\Lambda} \mathbf{F}_{t}$, with the possibility that the sign of either component will change between different runs of the estimation method. Thus, if the sign of a factor changes, the sign of the corresponding loading will change as well. For forecasting purposes, we are concerned only with the product $\hat{\Lambda} \mathbf{F}_{t}$ and therefore impose no restriction to maintain a consistent sign over the two subsamples. As a result, we analyze the absolute magnitude of the loadings and ignore any variation in their signs between the post-1964 and post-1983 periods.

There is little difference between the factor loadings across the samples for most factors, which suggests a stable relationship. For the first factor, consumer price indexes, the ordering of the factor loadings changes somewhat. For example, the core PCEPI (which excludes food and energy prices) is highly correlated in the full sample but less so in the post-Great Moderation sample. A few other factors change composition across samples. Foreign prices and the survey data change the ordering of the largest factor loadings, but the top three data series remain the same. The series that comprise the inflation expectations factor change composition, but this is likely due to data availability.

\section{Forecasting Specifics}

As noted earlier, we augment our FAVAR model with eight or nine factors. Eight factors are used in the full sample; the ninth factor is derived from the inflation expectations series and is included in the post-1983 period. In the first experiment, we estimate the three modelsAO, AR(12), and FAVAR - through December 1989. Our first out-of-sample forecasts inflation using data available up through January 1990. We then forecast horizons from 0 (January 1990) to 12 months ahead (January 1991). Forecasts are constructed using direct methods: We regress 


\section{Table 2}

Three Largest Factor Loadings Within Each Category: Full Post-February 1964 Sample

\section{Consumer price indexes}

FRB Cleveland: Median CPI, 1-month percent change $\quad-1.21$

FRB Atlanta: Sticky CPI, 1-month percent change 1.18

PCE chain-type price index, market-based excluding food and energy $\quad-1.18$

Producer prices

PPI: Final demand $\quad 1.02$

$\begin{array}{ll}\text { PPI: Final demand goods } & 1.01\end{array}$

$\begin{array}{ll}\text { PPI: Final demand excluding food and energy } & 1.01\end{array}$

\section{Commodity prices}

KR-CRB Spot Commodity Price Index: All Commodities $\quad 1.38$

CRB Spot Raw Industrials Price Index $\quad 1.22$

$\begin{array}{ll}\text { U.S. retail gasoline price: Regular grade } & 1.20\end{array}$

\section{House and commercial property prices}

Case-Shiller Composite 20-City House Price Index 1.01

$\begin{array}{ll}\text { FHFA House Price Index, Purchase Only } & 1.01\end{array}$

CoreLogic National House Price Index (SA, Jan. $2000=100) \quad 1.00$

\section{Labor markets}

Civilian unemployment rate $\quad 1.37$

$\begin{array}{ll}\text { Civilian unemployment rate gap estimate } & 1.37\end{array}$

Average hourly earnings: Private goods-producing, all employees $\quad 1.36$

\section{Financial}

10-Year Treasury yield, constant maturity 1.61

5-Year Treasury yield, constant maturity 1.59

30-Year Treasury yield, constant maturity $\quad 1.55$

Inflation expectations

TIPS spread, 5-year 1.001

$\begin{array}{ll}\text { TIPS spread, 7-year } & 1.001\end{array}$

$\begin{array}{ll}\text { TIPS spread, 10-year } & 1.001\end{array}$

Surveys

ISM: Nonmanufacturing Prices Paid index $\quad-1.28$

NFIB: Percent of firms planning to raise average selling prices, net $\quad-1.17$

ISM: Manufacturing Prices Paid index $\quad-1.07$

Foreign prices

$\begin{array}{ll}\text { Euro area harmonized overall CPI } & 1.17\end{array}$

U.S. Import Price Index, All Imports $\quad 1.15$

U.S. Import Price Index, Nonpetroleum Imports $\quad 1.15$

NOTE: CRB, Commodity Research Bureau; FHFA, Federal Housing Finance Agency; ISM, Institute for Supply Management; NFIB, National Federation of Independent Business; PPI, producer price index; SA, seasonally adjusted; TIPS, Treasury inflation-protected securities.

SOURCE: Authors' calculations. 


\section{Table 3}

\section{Three Largest Factor Loadings Within Each Category: Full Post-January 1983 Sample}

\section{Consumer price indexes}

FRB Cleveland: 16\% Trimmed mean CPI, 1-month percent change 1.35

FRB Dallas: Trimmed mean, 1-month PCE inflation rate $\quad 1.34$

FRB Atlanta: Sticky CPI, 1-month percent change $\quad 1.32$

\section{Producer prices}

PPI: Final demand 1.02

PPI: Final demand goods $\quad 1.01$

$\begin{array}{ll}\text { PPI: Final demand excluding food and energy } & 1.01\end{array}$

\section{Commodity prices}

KR-CRB Spot Commodity Price Index: All Commodities $\quad 1.42$

CRB Spot Raw Industrials Price Index $\quad 1.30$

CRB Spot Livestock and Products Price Index 1.12

House and commercial property prices

Case-Shiller Composite 20-City House Price Index 1.23

CoreLogic National House Price Index (SA, Jan. $2000=100) \quad 1.18$

$\begin{array}{ll}\text { FHFA House Price Index: Purchase Only } & 1.07\end{array}$

Labor markets

Civilian unemployment rate $\quad 1.46$

Civilian unemployment rate gap estimate $\quad 1.43$

Average hourly earnings: Private goods-producing, all employees $\quad 1.29$

Financial

10-Year Treasury yield, constant maturity $\quad-1.60$

5-Year Treasury yield, constant maturity $\quad-1.58$

Yield on Treasury long-term composite bond $\quad-1.53$

Inflation expectations

TIPS spread, 30-year

FRB Cleveland, 5-Year expected inflation rate $\quad-1.10$

FRB Cleveland, 7-Year expected Inflation rate $\quad-1.10$

Surveys

ISM: Nonmanufacturing Prices Paid Index $\quad-1.40$

ISM: Manufacturing Prices Paid Index $\quad-1.26$

NFIB: Percent of firms planning to raise average selling prices, net $\quad-1.22$

Foreign prices

U.S. Import Price Index, All Imports $\quad-1.41$

Euro area harmonized overall CPI $\quad-1.42$

U.S. Import Price Index: Nonpetroleum Commodities $\quad-1.34$

NOTE: CRB, Commodity Research Bureau; FHFA, Federal Housing Finance Agency; ISM, Institute for Supply Management; NFIB, National Federation of Independent Business; PPI, producer price index; SA, seasonally adjusted; TIPS, Treasury inflation-protected securities.

SOURCE: Authors' calculations. 


\section{Figure 1}

\section{CPI and PCEPI Inflation}

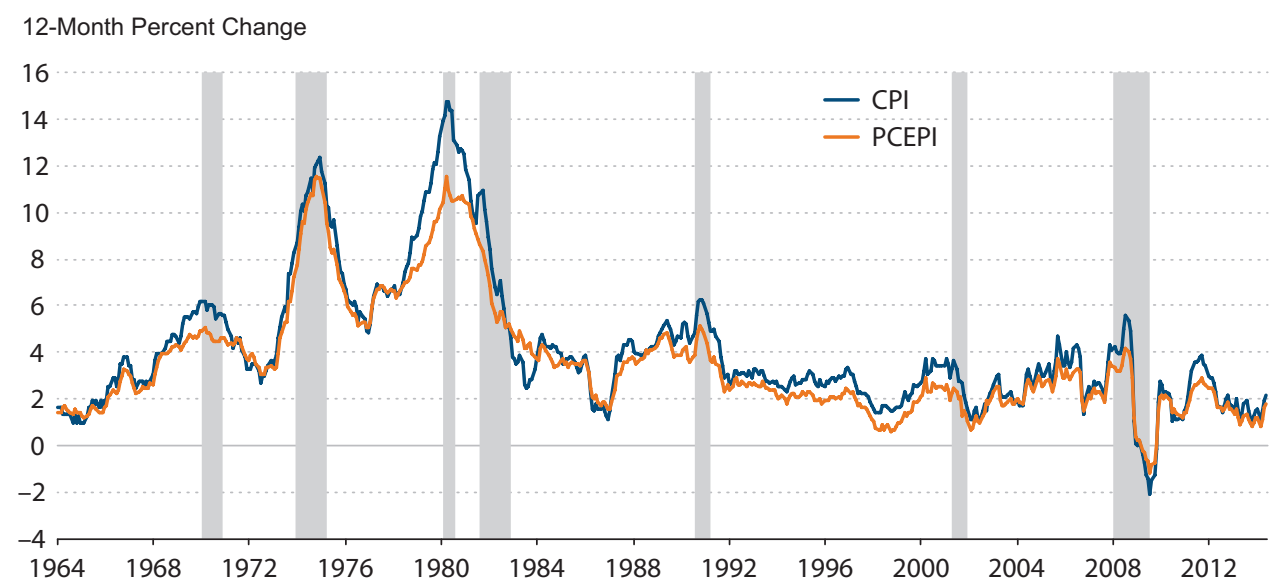

NOTE: The shaded bars indicate recessions as determined by the National Bureau of Economic Research.

SOURCE: Bureau of Economic Analysis, Bureau of Labor Statistics, National Bureau of Economic Research, and Haver Analytics.

directly the forward data on the available information. We use a recursive estimation scheme so that all past information is incorporated into the model estimates. We have three FAVAR models: 1 lag, 6 lags, and 12 lags. Because estimation of the FAVAR is computationally intensive, we reestimate the model only once per year in January, when we assume all data from the previous year are available. The forecasts are constructed monthly, which means the principal components are updated monthly, but the forecasts are constructed using that year's estimate of the model parameters.

\section{Results}

Figure 1 plots the actual inflation series we forecast. Inflation-whether measured by CPI or PCEPI-was rising, on net, from the beginning of our sample to roughly 1981 and was highly variable. Inflation fell sharply after the Volcker disinflation and has averaged around 3 percent—and generally has been much less volatile-after 1983.

Table 4 shows the root mean squared errors (RMSEs) for the two sample periods and all three models. An RMSE is a standard measure of forecast accuracy, as it penalizes a forecast if it has a higher variance and bias of its forecast errors (actual less predicted). A lower RMSE indicates a better forecast relative to another forecast. In the table, the RMSEs are benchmarked to a baseline forecast's RMSE, which we define as the random walk (AO). Thus, in Table 4 a value less than 1 indicates that the model outperforms the $\mathrm{AO}$ model (better forecast accuracy) and any value greater than 1 indicates that the AO has a smaller RMSE over the relevant forecast horizon. 


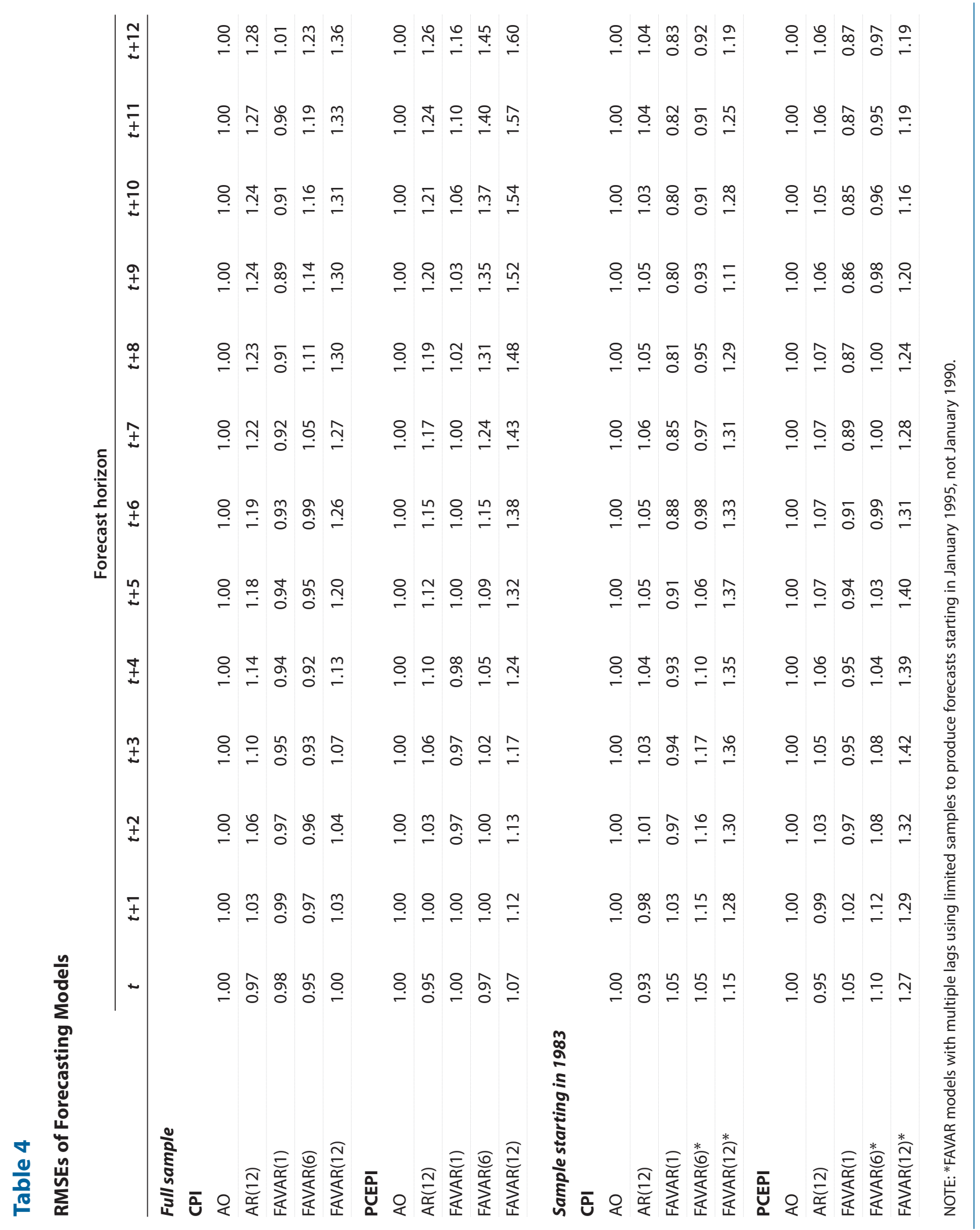


We now consider some key findings from the full sample. First, the AO model performs reasonably well across most horizons. The AO model clearly outperforms the AR(12) modelexcept for the contemporaneous period $(t=0)$ - for both measures of inflation.

In the full sample, the FAVAR(1) model is generally more accurate in forecasting CPI inflation than the AO model for times $t$ to $t+11$. The FAVAR(6) model performs much better through the first half of the forecast horizon (up through 6 months). The forecasting accuracy of the FAVAR(12) model is worse than the FAVAR(1) and FAVAR(6) models across all horizons. The longer the forecast horizon, the worse the FAVAR(12) model performs-indeed, worse than the AR(12) model. In the full sample, the FAVAR models generally do not forecast PCE inflation as well as the $\mathrm{AO}$ model. The random walk model tends to dominate all other models for forecasting PCE inflation in the full sample.

Table 4 also shows the forecasting performance in the post-1983 sample. In this experiment, the model is estimated with data from January 1983 through December 1994 and then out-of-sample forecasting begins in January 1995. In this experiment, we add the inflation expectations factor (for a total of nine factors). As before, the models are then reestimated a year later and out-of-sample forecasts are produced. Table 4 clearly indicates that adding the inflation expectations factor to the FAVAR model produces markedly smaller RMSEs for both inflation measures than either the AO or AR(12) models. Indeed, at 6 and 12 months ahead, the FAVAR(1) forecast for CPI inflation produces RMSEs that are 12 percent and 17 percent smaller, respectively, than the AO model. The RMSEs are a bit larger for the 6-lag FAVAR. For PCEPI inflation, the RMSEs are a bit larger than for CPI inflation, but again the FAVAR(1) and FAVAR(6) models perform measurably better than the AO or AR(12) models. The FAVAR(12) model has a much higher RMSE for both CPI and PCEPI inflation than the other models across all horizons.

Figures 2 through 5 plot actual inflation and the forecast for contemporaneous inflation for the FAVAR(1) and FAVAR(6) models for both samples. The figures also plot out-of-sample forecasts for January 2014-January 2015. As shown in Figure 2, using the full-sample estimation, the FAVAR(1) model forecasts that CPI inflation would rise to about 2.5 percent in January 2015. However, the FAVAR(6) model forecasts that inflation would remain about unchanged. Figure 3 shows the same pattern for PCEPI inflation. Using the post-1983 sample, both models predict higher inflation in 2014 and early 2015 relative to the end of 2013. Figures 4 and 5 are consistent with the view of the FOMC, which foresees inflation eventually returning to its 2 percent inflation target.

\section{A MEASURE OF PRICE PRESSURES}

In the previous section, we considered the problem of forecasting the value of inflation at some horizon. To evaluate those forecasts, we compared the point value of the forecasted distribution with the realized value. Forecasts farther from the realization yield larger penalties for the model. In some circumstances the distance from the realization is less important than, say, the direction of the change. Recently, the Federal Reserve announced a target zone for inflation. When inflation is above the target zone, the Fed has a substantially higher probability 


\section{Figure 2}

\section{Actual Versus Forecasted CPI Inflation: Full Sample}

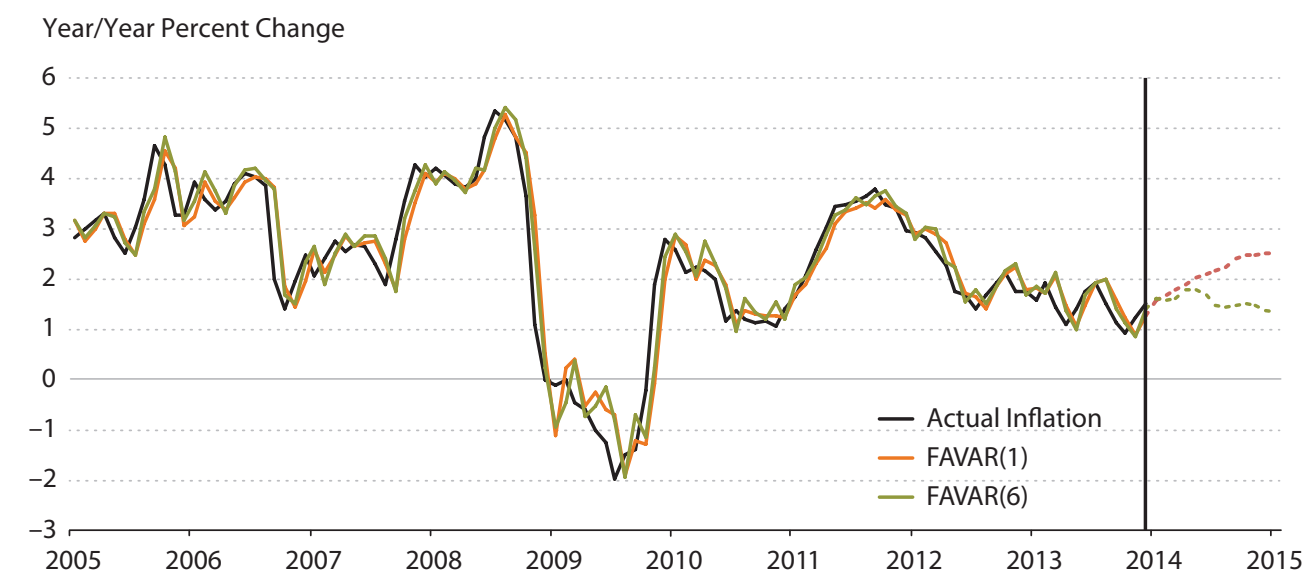

NOTE: Forecasts are plotted for January 2014 to January 2015.

SOURCE: Authors' calculations.

\section{Figure 3}

\section{Actual Versus Forecasted PCEPI Inflation: Full Sample}

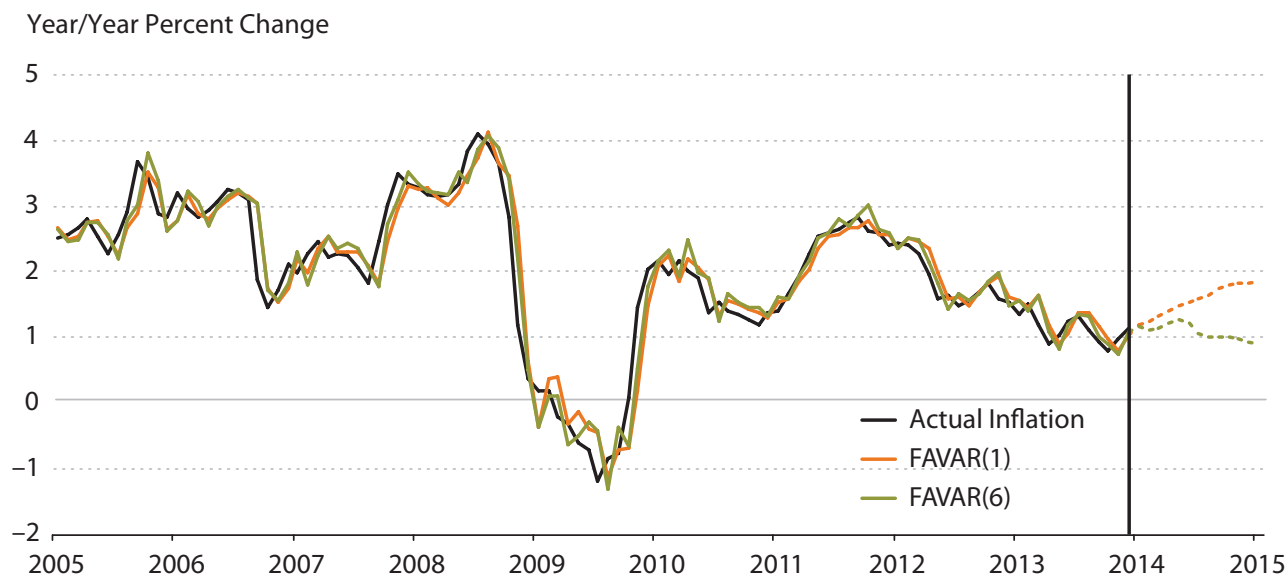

NOTE: Forecasts are plotted for January 2014 to January 2015.

SOURCE: Authors' calculations. 


\section{Figure 4}

\section{Actual Versus Forecasted CPI Inflation: Post-1983 Sample}

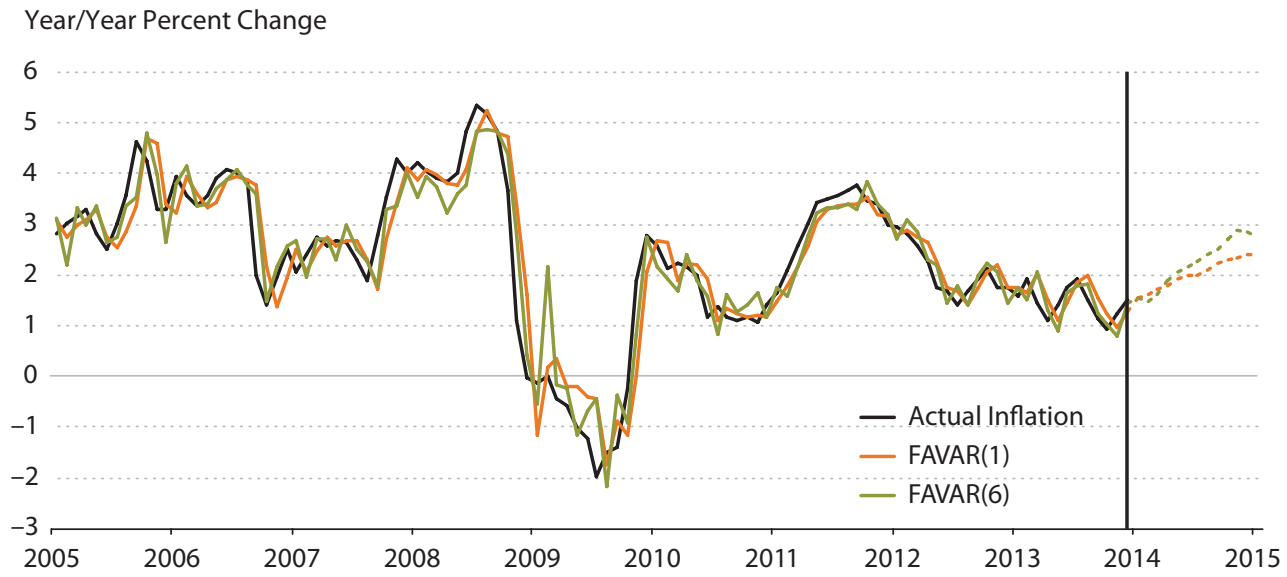

NOTE: Forecasts are plotted for January 2014 to January 2015.

SOURCE: Authors' calculations.

\section{Figure 5}

\section{Actual Versus Forecasted PCEPI Inflation: Post-1983 Sample}

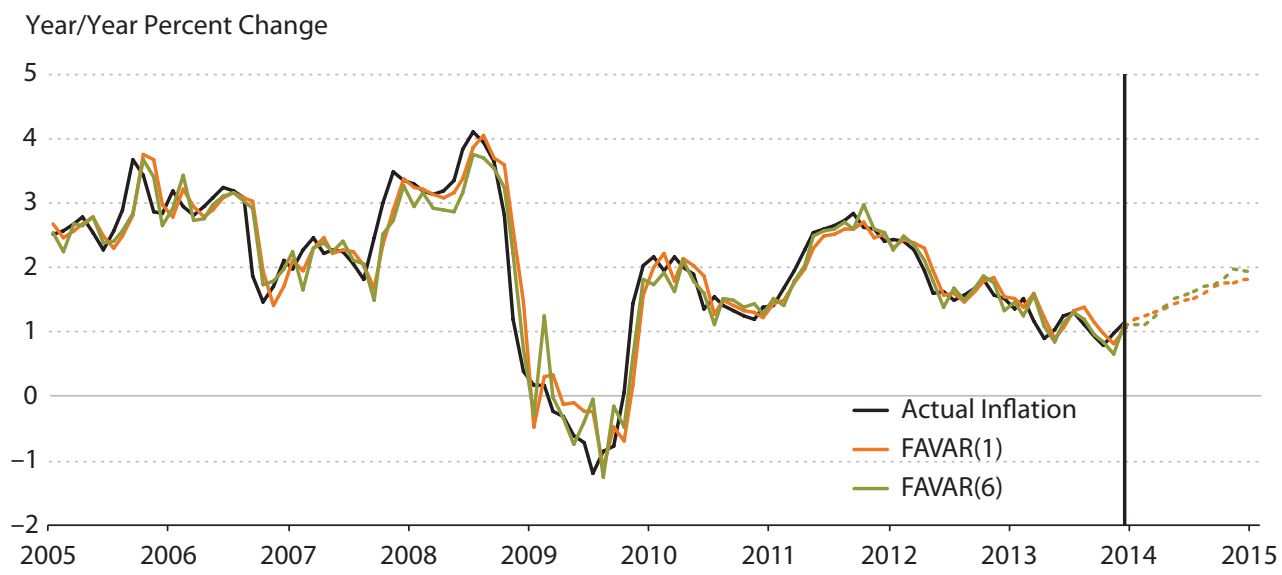

NOTE: Forecasts are plotted for January 2014 to January 2015.

SOURCE: Authors' calculations. 
of increasing the federal funds rate to combat inflation; when inflation is below the target zone, the Fed has a higher probability of lowering the federal funds rate to stimulate the economy. Thus, it might be important to assess the probability that inflation will move above the target zone over some horizon. In this section, we consider a forecast of this sort. We use this forecasting model to construct an index that we call the price pressure measure (PPM), which reflects the likelihood that inflation will be above the target zone in the next year.

\section{The Model}

Our objective is to forecast the probabilities that inflation will rise above or fall below the target zone. We define the discrete variable $\Pi_{t} \in\{1,2,3,4\}$, where the discrete outcomes correspond to

$$
\begin{array}{ccc}
\Pi_{t}=1 & \text { if } & \pi_{t} \leq 0 \\
\Pi_{t}=2 & \text { if } & 0<\pi_{t} \leq 1.5 \\
\Pi_{t}=3 & \text { if } & 1.5<\pi_{t} \leq 2.5 \\
\Pi_{t}=4 & \text { if } & 2.5<\pi_{t}
\end{array}
$$

and $\pi_{t}$ is the period- $t$ inflation rate (12-month percent changes). The bounds on the right-hand side of the conditions outlined in (5) are determined by the FOMC statement about the target zone. The third condition establishes a set of bounds symmetric around the Fed's inflation target: $1.5 \leq \pi_{t}<2.5$. We are interested in forecasting $\Pi_{t+h \mid t}$, the $h$-period-ahead value of the discrete variable conditional on the information at time $t$. Let $\pi_{t+h \mid t}$ be the "forecast" of inflation conditional on time- $t$ information. Suppose that this forecast is given by

$$
\pi_{t+h \mid t}=G\left(\pi_{t-1}, \mathbf{F}_{t}\right)+\varepsilon_{t}
$$

then the forecast $\operatorname{Pr}\left[\Pi_{t+h \mid t}=k\right]$, for example, can be obtained by determining the probability that $\pi_{t+h \mid t}>2.5$. Because the $\varepsilon_{t}$ are assumed normal, the model is the familiar ordered probit augmented with the set of factors, $\mathbf{F}_{t}$.

\section{Estimation}

As in the previous section, the model is estimated with the Gibbs sampler, a Bayesian method that iteratively draws each parameter from its conditional distribution. In the sampler, we treat the factor identified by principal components as a known quantity. Multiple draws from the sampler approximate the full joint density. We sample the latent forecast $\left\{\pi_{t+h \mid t}\right\}_{t=1}^{T}$, conditional on the factors and the model parameters, from a truncated normal, where the truncation points are given by (5). Here, $T$ represents the $h$ periods before the end of the estimation sample as we lose some data because of the direct forecasting scheme. Assuming a normal prior, we can draw the model parameters from the normal conjugate posterior distribution, conditional on $\left\{\pi_{t+h \mid t}\right\}_{t=1}^{T}$. The forecasts will be probabilities, $\operatorname{Pr}\left[\Pi_{t+h \mid t}=k\right]$, which are determined by obtaining the area under the normal cumulative distribution function between the truncation points conditional on the forecasted value $\pi_{t+h \mid t} \cdot{ }^{13}$ 


\section{Forming the Index}

The objective of forming the PPM is to assess the likelihood that inflation will rise above the target. We computed $\left\{\operatorname{Pr}\left[\pi_{t+h \mid t}>2.5\right]\right\}_{h=0}^{12}$ using the ordered probit model. We can compute a weighted sum of these probabilities to form our PPM:

$$
P P M=\sum_{h=0}^{12} w_{h} \operatorname{Pr}\left[\pi_{t+h \mid t}>2.5\right],
$$

where $w_{h}$ is the weight placed on horizon $h$ and $\Sigma_{h} w_{h}=1$. The nature of the weights depends on whether longer or shorter horizon forecasts are more valued. In this case, we opt for equal weighting.

\section{Results}

Our PPM measures the probability that the expected inflation rate (12-month percent changes) over the next 12 months-the forecast horizon-will exceed 2.5 percent. This bin (2.5 percent) exceeds the Fed's 2 percent inflation target. We calculate our PPMs from these two modes. These PPMs are plotted in Figure 6 for CPI and PCEPI inflation using the 1- and 6-lag ordered probit models. ${ }^{14}$ We plot the smoothed series, which is a six-month moving average. Figure 6 shows that, over most of this sample period (January 1990-January 2014), the PPM for CPI inflation was greater than 0.5. By contrast, the probabilities for PCEPI inflation exceeded 0.5 by an appreciably smaller percentage over the sample period. Since the end of the recent recession, the PPMs have been significantly below 0.5 for PCEPI inflation but moderately less so for CPI inflation. In one sense, the models are picking up the fact that inflation was higher before the recession and that CPI inflation is generally higher on average than PCEPI inflation. For the January 1990-December 2007 period, CPI inflation averaged 2.9 percent and PCEPI inflation averaged 2.3 percent. However, since January 2008, CPI inflation has averaged 2 percent and PCEPI inflation has averaged 1.7 percent.

At any point in time, the PPMs plotted in Figure 6 are unweighted averages of the probability that the forecasted inflation rate will average more than 2.5 percent over the next 12 months. However, policymakers know that a standard error around the point estimate is associated with any forecast. For example, the Bank of England's fan charts contain both point estimates and error bands around these point estimates that can be thought of as probabilities. In the simplest terms, if monetary policymakers project that inflation over the following year will be 2 percent, there is some probability that inflation will be less than 2 percent and some probability that inflation will be more than 2 percent.

The ordered probit model estimated earlier provides probabilities that inflation will exceed 2.5 percent, on average, over the next 12 months. But our model also allows us to assess the probability that inflation will average something different. In this case, we structure the model to assess the probability that inflation will fall within one of four bins: less than zero (deflation); 0 percent to 1.5 percent; 1.5 percent to 2.5 percent; and more than 2.5 percent. The last bin is our PPM plotted in Figure 6; Figure 7 plots the other three probabilities. For ease of discussion, we condense the second and third bins into one, leaving two sets of 


\section{Figure 6}

\section{Price Pressure Measure: Probability That Inflation Exceeds 2.5 Percent}
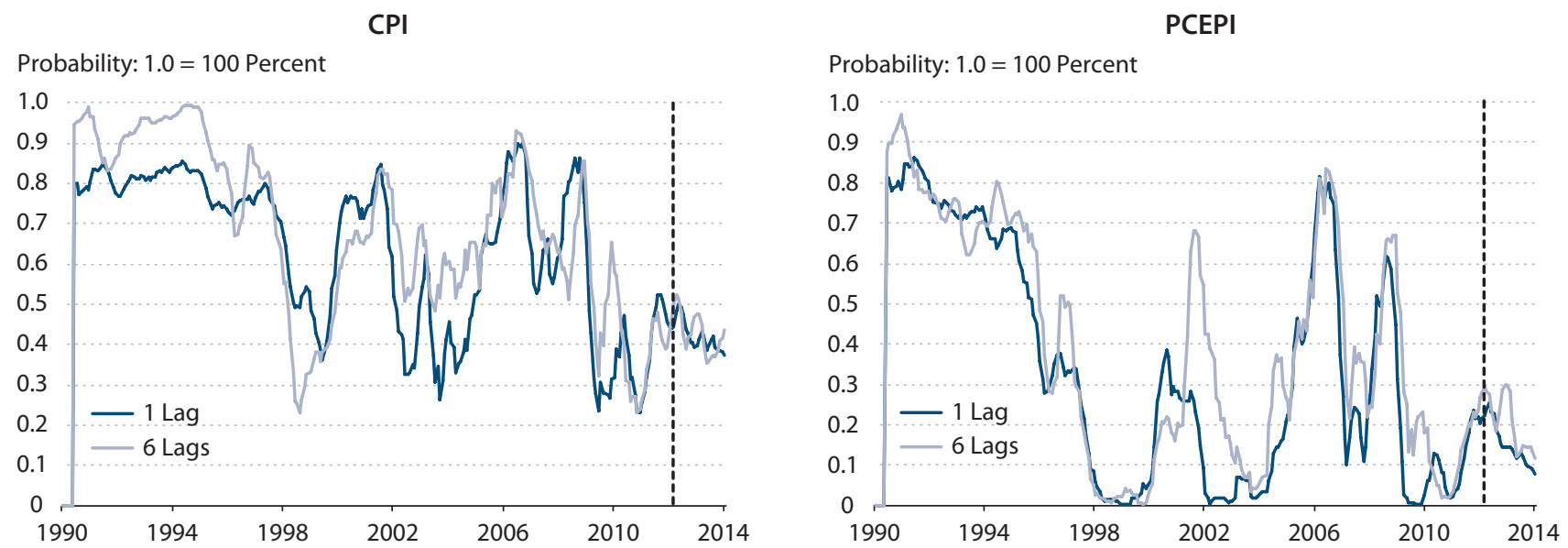

NOTE: Sample is limited to 1983 to present. The vertical dashed line indicates March 2012.

SOURCE: Authors' calculations.

probabilities: Inflation will be less than zero (deflation) over the next 12 months and inflation will average between 0 percent and 2.5 percent.

In March 2012, policymakers observed that the CPI had increased by 2.3 percent over the previous year (March 2011-March 2012). The outlook of professional forecasters, as judged by the Blue Chip Consensus (BCC), was that the CPI inflation rate (four-quarter percent changes) would average 2.1 percent from 2012:Q2 to 2013:Q2. However, as noted earlier, policymakers generally eschew point estimates in favor of probabilities. ${ }^{15} \mathrm{In}$ this case, as shown in Figure 7, it is the probability that inflation will be above or below the forecast consensus.

In March 2012, the model predicted a 45 percent probability that CPI inflation would average more than 2.5 percent from April 2012 to April 2013 (see Figure 6). This relatively high probability could have reflected the fact that crude oil prices rose by 24 percent from September 2011 to March 2012. However, the model also predicted an equal probability that inflation would average between 0 percent and 2.5 percent, with only a 10 percent probability that inflation would average less than zero over the next 12 months. (This date is noted by the vertical dashed line in the figure.) ${ }^{16}$ But forecasters and policymakers were instead surprised because inflation fell from 2.3 percent in April 2012 to 1.1 percent in April 2013. The model performed reasonably well if one takes into account the probability of deflation: There was a greater than 50 percent probability that inflation would be less than 2.5 percent.

A year later, in March 2013, the model lowered the probability that inflation would average more than 2.5 percent over the next year (April 2013-April 2014) from 45 percent to 43 percent (see Figure 6). However, the model raised the probability that inflation would be between 0 percent and 2.5 percent over the following year from 45 percent to 50 percent. Likewise, the 


\section{Figure 7}

\section{Price Pressure Measure: Ordered Probit Model}

CPI, 1 Lag

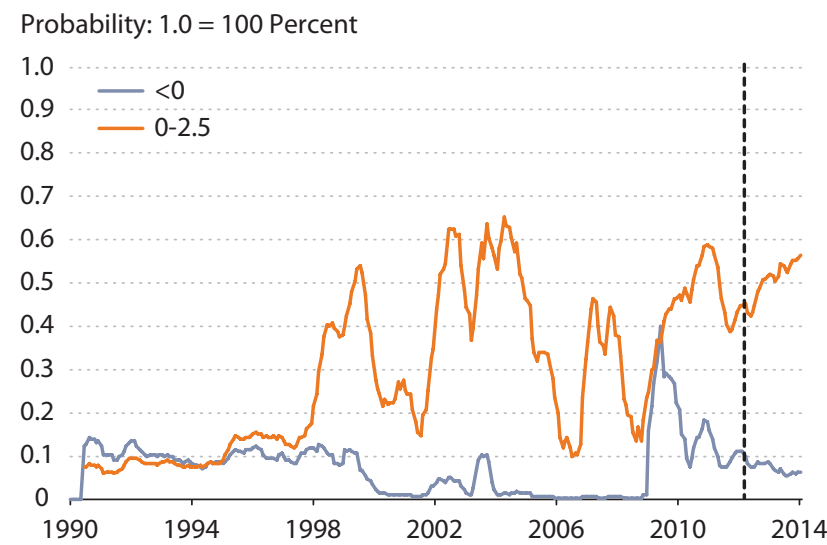

CPI, 6 Lags

Probability: $1.0=100$ Percent

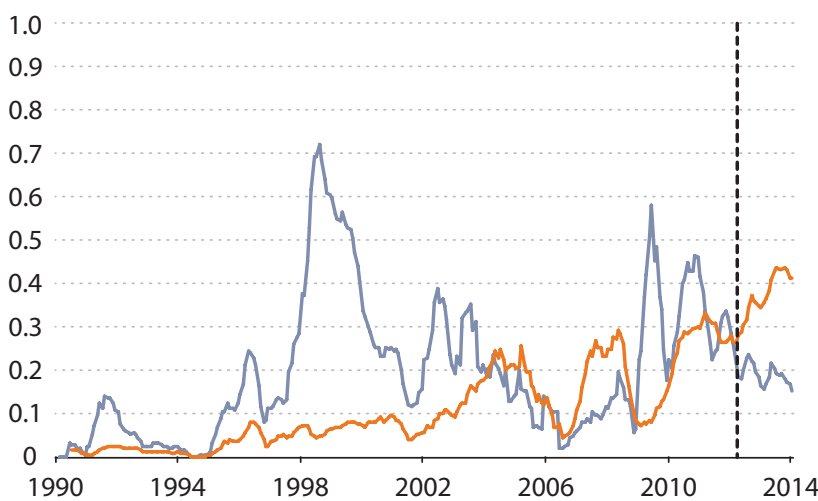

PCEPI, 1 Lag

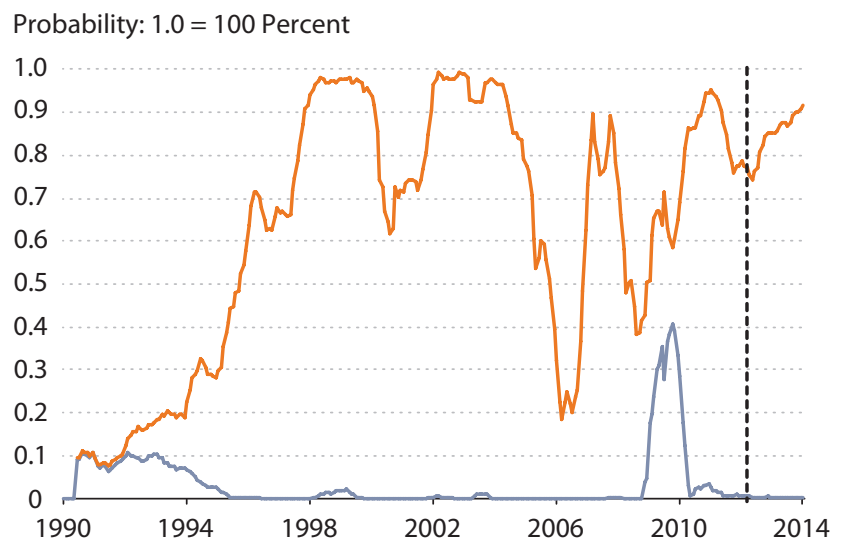

PCEPI, 6 Lags

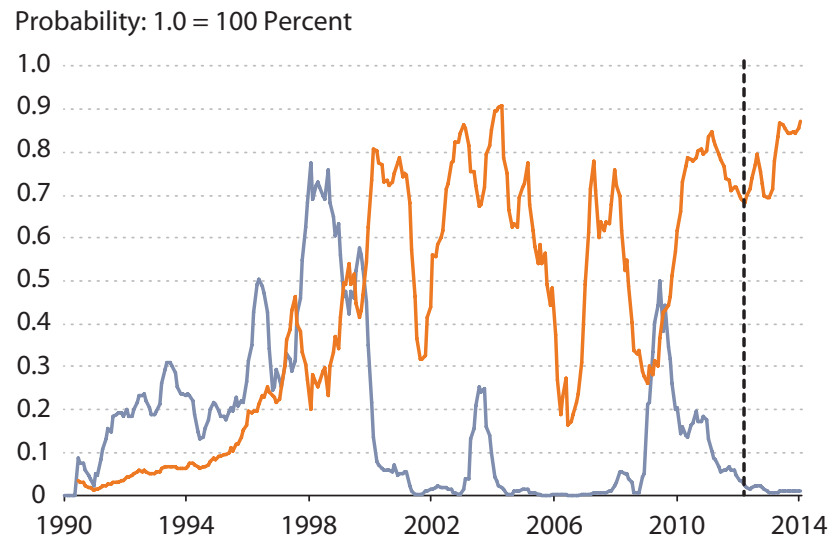

NOTE: Sample is limited to 1983 to present. The vertical dashed line indicates March 2012.

SOURCE: Authors' calculations.

model lowered the probability of deflation from 10 percent to 7 percent. By contrast, in March 2013 the BCC forecasters predicted the CPI inflation rate (four-quarter percent changes) would average 2.0 percent from 2013:Q2 to 2014:Q2 - virtually unchanged from their year-ahead forecast published a year earlier.

The preceding discussion focuses on the CPI inflation rate. Although many contracts and prices are indexed to the CPI, FOMC policymakers instead prefer to target the PCEPI inflation rate. The upper-right panel in Figure 7 plots the smoothed PPMs for the PCEPI inflation rate from the probit 1-lag model. A similar story emerges here as well. In March 2012, as seen in Figure 6 , the model predicted only a 22 percent probability that inflation would average more than 2.5 percent over the next 12 months (April 2012-April 2013). The model predicted a 77 
percent probability that inflation would average between 0 and 2.5 percent. The probability that inflation would average less than zero (deflation) was less than 1 percent. Although the BCC does not forecast the PCEPI inflation rate, forecasts for the FOMC's preferred inflation measure are reported in the Philadelphia Fed's SPF. In its February 2012 report, the SPF predicted the PCEPI would increase from 1.7 percent (quarterly rate, annualized) in 2012:Q1 to 2 percent in 2013:Q1. Mirroring the dip in the CPI inflation rate, the PCEPI inflation rate unexpectedly slowed from 2 percent in April 2012 to 1 percent in April 2013. ${ }^{17}$ In this case, the model performed well, perceiving a relatively high probability that inflation would remain below 2.5 percent.

The unexpected slowing in inflation, perhaps not surprisingly, affected the probability distributions a year later, in March 2013. By then, the model estimated the probability that PCEPI inflation would average between 0 and 2.5 percent over the next 12 months (April 2013-April 2014) had increased from 77 percent to 85 percent. The probability of deflation was lowered from 0.8 percent to 0.3 percent. As shown in Figure 6, the probability that inflation would average more than 2.5 percent declined from 22 percent to 14 percent. Despite this marked shift in the probability distribution, in mid-February 2013 the SPF was still projecting that PCEPI inflation would increase to 2 percent in 2014:Q1. Once again, the actual data are more consistent with our model: From April 2013 to March 2014 (the latest available data), the 12-month change in the PCEPI inflation rate increased from 1 percent to 1.2 percent. The two lower charts in Figure 7 show the PPMs using the 6-lag probit for the post-1983 sample. They show trends broadly similar to the 1-lag model.

\section{Out-of-Sample PCEPI Inflation Forecasts}

Table 4 indicates that the best model for forecasting inflation one year ahead is the FAVAR(1) for CPI inflation estimated using the post-1983 sample. Although the FAVAR(1) RMSEs for PCEPI inflation are slightly larger, this section nonetheless focuses on this measure because the FOMC targets the PCEPI inflation rate. Recall that Figure 5 plots the PCEPI inflation forecasts for January 2014-January 2015. For purposes of comparison, FOMC participants in December 2013 projected that the PCEPI inflation rate would increase by 1.5 percent in 2014 (2013:Q4-2014:Q4). ${ }^{18}$ Thus, our preferred inflation forecasting model expected inflation to rise by slightly more than the FOMC's projection, from 1 percent in December 2013 to 1.8 percent in December 2014 and in January 2015. ${ }^{19}$

Figure 8 shows the probability distribution of this out-of-sample forecast from January 2014 to January 2015. The upper-left panel indicates that the model predicts a very smallroughly zero-probability of deflation over this horizon. For this forecast, we can separate the 0 percent to 2.5 percent probability distribution into two bins: 0 to 1.5 percent (upper-right panel) and 1.5 percent to 2.5 percent (lower-left panel). In the upper-right panel, the model predicts a more than 50 percent probability that PCEPI inflation would remain in the 0 to 1.5 percent range through the first five months of 2014. Thereafter, the model predicts a higher probability-averaging slightly less than 50 percent-that PCEPI inflation would rise to more than 1.5 percent but remain below 2.5 percent. The lower-right panel shows an increasing probability-over the second half of 2014-that inflation would increase by more than 2.5 percent by the end of the forecast horizon. 


\section{Figure 8}

\section{PCEPI Inflation Probabilities}

Probability That PCEPI Inflation Will Be Negative (Jan. 2014-Jan. 2015)

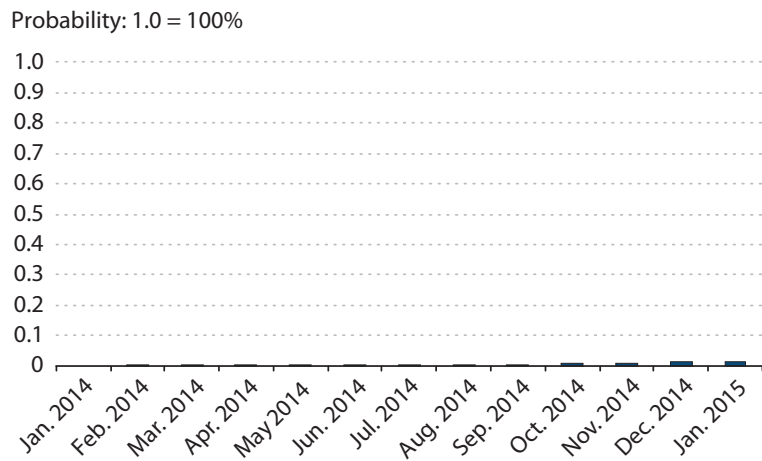

Probability That PCEPI Inflation Will Be $1.5 \%$ to $2.5 \%$ (Jan. 2014-Jan. 2015)

Probability: $1.0=100 \%$

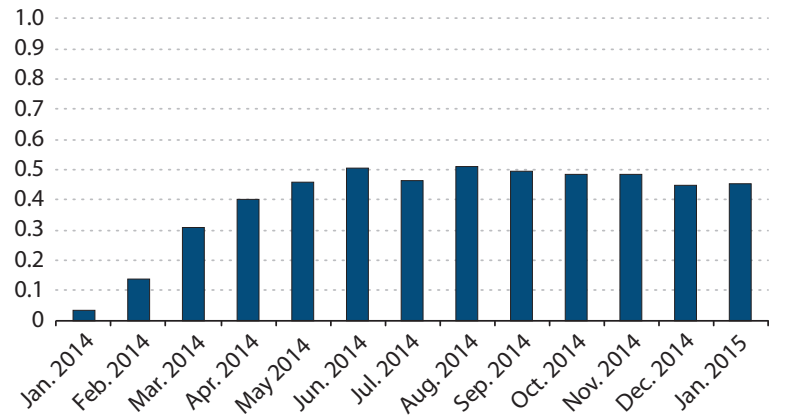

Probability That PCEPI Inflation Will Be $0 \%$ to $1.5 \%$ (Jan. 2014-Jan. 2015)

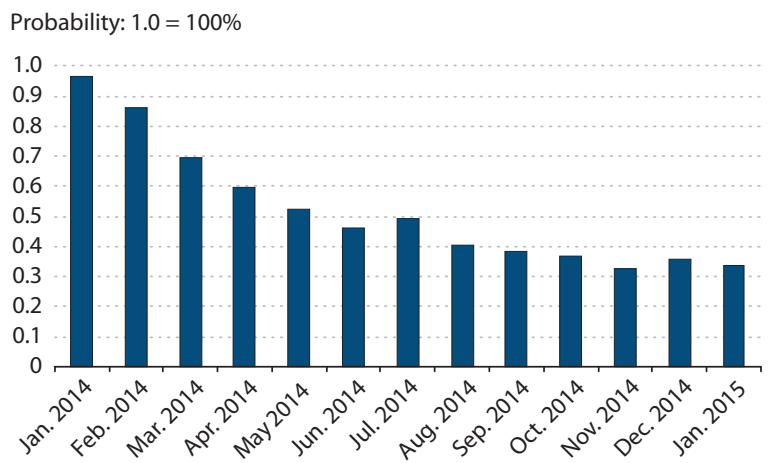

Probability That PCEPI Inflation Will Be Above 2.5\% (Jan. 2014-Jan. 2015)

Probability: $1.0=100 \%$

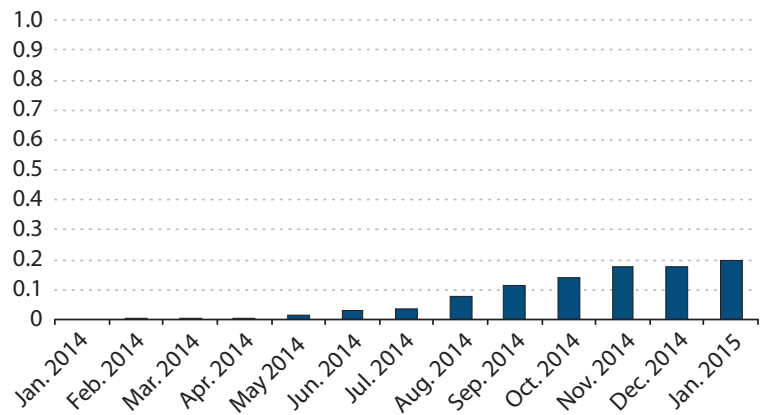

\section{CONCLUSION}

The FOMC, like most major central banks, devotes significant resources to forecasting key economic variables such as real GDP growth, employment, and inflation. The outlook for these variables also matters a great deal to businesses and financial market participants. For example, when decisions are made to expend scarce resources or price financial assets, such decisions - which must be made in the present-are based on expectations of future economic conditions. In this article, we present a factor-augmented Bayesian vector autoregressive forecasting model that significantly outperforms both a benchmark random walk model and a pure time-series model. The empirical literature has shown that random walk models tend to be among the most accurate across a variety of simple time-series model specifications. A key 


\section{Jackson, Kliesen, Owyang}

innovation in our article is the use of nine factors in an ordered probit model to assess the probability distribution of the model's point forecasts. We term these probabilities a price pressure measure. Our measure shows a relatively high probability that inflation in 2014 would be higher than that projected by the FOMC in its December 2013 Summary of Economic Projections. ${ }^{20}$ 


\section{APPENDIX}

\section{Data Used to Construct Factors, Their Transformation, and Their Source}

\begin{tabular}{|c|c|c|c|}
\hline \multicolumn{2}{|c|}{ Description } & \multirow[t]{2}{*}{ Transformation } & \multirow[t]{2}{*}{ Source } \\
\hline Cor & ssumer price indexes & & \\
\hline 1 & PCE: Chain-type price index $(S A, 2009=100)$ & DLN & BEA \\
\hline 2 & PCE: Goods: Chain-type price index $(S A, 2009=100)$ & DLN & BEA \\
\hline 3 & PCE: Services: Chain-type price index (SA, $2009=100)$ & DLN & BEA \\
\hline 4 & PCE: Less food and energy: Chain-type price index (SA, $2009=100)$ & DLN & BEA \\
\hline 5 & $\begin{array}{l}\text { PCE: Food and beverages purchased for off-premises consumption: } \\
\text { Chain-type price index }(S A, 2009=100)\end{array}$ & DLN & BEA \\
\hline 6 & PCE: Energy goods and services: Chain-type price index $(S A, 2009=100)$ & DLN & BEA \\
\hline 7 & Market-based PCE: Chain-type price index (SA, 2009 = 100) & DLN & BEA \\
\hline 8 & Market-based PCE excluding food and energy: Chain-type price index (SA, $2009=100$ ) & DLN & BEA \\
\hline 9 & PCE: Imputed rental of owner-occupied nonfarm housing price index (SA, $2009=100)$ & DLN & BEA \\
\hline 10 & CPI-U: All items (SA, 1982-84 = 100) & DLN & BLS \\
\hline 11 & CPI-U: All items less food and energy (SA, 1982-84 = 100) & DLN & BLS \\
\hline 12 & CPI-U: Food (SA, 1982-84 = 100) & DLN & BLS \\
\hline 13 & CPI-U: Energy (SA, 1982-84 = 100) & DLN & BLS \\
\hline 14 & CPI-U: Owners' Equivalent Rent of Primary Residence (SA, December $1982=100$ ) & DLN & BLS \\
\hline 15 & FRB Dallas: Trimmed mean 1-month PCE inflation, annual rate (\%) & LVL & FRBDAL \\
\hline 16 & FRB Cleveland Median CPI (SA, \% change) & LVL & FRBCLE \\
\hline 17 & FRB Cleveland $16 \%$ Trimmed mean CPI (SA, \% change) & LVL & FRBCLE \\
\hline 18 & FRB Atlanta Sticky price CPI (SA, \% change) & LVL & FRBATL \\
\hline 19 & FRB Atlanta Core sticky CPI (SA, \% change) & LVL & FRBATL \\
\hline 20 & FRB Atlanta Sticky CPI excluding shelter (SA, \% change) & LVL & FRBATL \\
\hline 21 & FRB Atlanta Core sticky CPI excluding shelter (SA, \% change) & LVL & FRBATL \\
\hline 22 & FRB Atlanta Flexible CPI (SA, \% change) & LVL & FRBATL \\
\hline 23 & FRB Atlanta Core flexible CPI (SA, \% change) & LVL & FRBATL \\
\hline \multicolumn{4}{|c|}{ Producer prices } \\
\hline 24 & PPI: Final demand (SA, November $2009=100)$ & DLN & BLS \\
\hline 25 & PPI: Final demand goods (SA, November $2009=100)$ & DLN & BLS \\
\hline 26 & PPI: Final demand services (SA, November 2009 = 100) & DLN & BLS \\
\hline 27 & PPI: Final demand less foods and energy (SA, April $2010=100)$ & DLN & BLS \\
\hline 28 & PPI: Intermediate demand processed goods (SA, $1982=100)$ & DLN & BLS \\
\hline 29 & PPI: Intermediate demand services (SA, November $2009=100)$ & DLN & BLS \\
\hline 30 & PPI: Intermediate demand processed energy goods (SA, $1982=100)$ & DLN & BLS \\
\hline \multicolumn{4}{|c|}{ Commodity prices } \\
\hline 31 & Refiners' acquisition cost of crude oil: Composite: DOE (\$/barrel) & DLN & EIA \\
\hline 32 & Natural gas price: Henry hub, Louisiana (\$/MMBTU) & DLN & WSJ \\
\hline 33 & U.S. retail gasoline price: Regular grade (Average, cents/gallon) & DLN & EIA \\
\hline 34 & U.S. retail diesel fuel price including taxes (Average, \$/gallon) & DLN & EIA \\
\hline 35 & Brent-WTI price spread $(\$ /$ barrel) & DLV & EIA/WSJ \\
\hline
\end{tabular}




\section{APPENDIX, cont'd}

Description

Commodity prices, cont'd.

36 KR-CRB Spot Commodity Price Index: All commodities $(1967=100)$

37 KR-CRB Spot Commodity Price Index: Metals (1967 = 100)

43 FHFA House Price Index: Purchase only, United States (SA, January $1991=100$ )

44 Freddie Mac House Price Index, United States (December $2000=100$ )

45 S\&P/Case-Shiller 20-City Composite Home Price Index (SA, January $2000=100$ )

46 CoreLogic National House Price Index (SA, January $2000=100$ )

47 GSA Commercial Property Price Index (NSA, August $2007=100$ )

48 Houses Under Construction: Fixed-Weighted Price Index (NSA, $2005=100)$

\section{Labor markets}

49 Average hourly earnings of production and nonsupervisory employees: Goods-producing industries (SA, \$/hr)

50 Average hourly earning of production and nonsupervisory employees: Private service-providing industries (SA, \$/hr)

51 Average hourly earnings: Goods-producing industries (SA, \$/hr)

52 Average hourly earnings: Private service-providing industries (SA, \$/hr)

53 Average weekly hours: Production and nonsupervisory employees: Overtime: Manufacturing (SA, hr)

54 Civilian unemployment rate: $16 \mathrm{yr}+(\mathrm{SA}, \%)$

55 Civilian unemployment rate, long-term unemployed ( 27 weeks or more)

\section{Financial}

60 Federal funds (effective) rate (\% p.a.)

612 -Year Treasury note yield at constant maturity (\% p.a.)

62 5-Year Treasury note yield at constant maturity (\% p.a.)

63 10-Year Treasury note yield, constant maturity (\% p.a.)

64 Long-term Treasury composite, over 10 years (\% p.a.)

$6530-$ Year Treasury bond yield, constant maturity (\% p.a.)

66 Yield spread, 10-yr Treasury note less 3-month Treasury bill

67 Adjusted monetary base including deposits to satisfy clearing balance contracts (SA, \$ bill.)

68 Money stock: M1 (SA, \$ bill.)

69 Money stock: M2 (SA, \$ bill.)
Transformation

Source

$\begin{array}{ll}\text { DLN } & \text { CRB } \\ \text { DLN } & \text { CRB } \\ \text { DLN } & \text { CRB } \\ \text { DLN } & \text { CRB } \\ \text { DLN } & \text { CRB } \\ \text { DLN } & \text { CRB } \\ \text { DLN } & \text { CRB }\end{array}$

DLN

FHFA

DLN

FHLMC

DLN

S\&P

DLN

CORE/H

DLN

GSA

DLN

CENSUS

DLN BLS

DLN BLS

DLN BLS

DLN BLS

DLN BLS

DLN BLS

DLN BLS

DLN BLS

DLV BLS \& AC

DLV BLS \& AC

DLV BLS \& AC

DLN FRB

DLN FRB

DLN FRB

DLN FRB

DLN TREASURY

DLN FRB

LVL FRB

DLN FRBSTL

DLN FRB

DLN FRB 


\section{APPENDIX, cont'd}

\section{Description}

Financial, cont'd.

70 Money stock: MZM (zero maturity) (SA, \$ bill.)

71 Nominal broad trade-weighted exchange value of the US\$ (January $1997=100$ )

72 St. Louis Fed Financial Stress Index (Above $0=$ Above-average financial stress)

73 Chicago Fed National Financial Conditions Index (+=Tighter than average)

\section{Inflation expectations}

74 TIPS spread, 5-year

75 TIPS spread, 7-year

76 TIPS spread, 10-year

77 TIPS spread, 20-year

78 TIPS spread, 30-year

79 Cleveland Fed 1-Year expected inflation rate (\%)

80 Cleveland Fed 2-Year expected inflation rate (\%)

81 Cleveland Fed 3-Year expected inflation rate (\%)

82 Cleveland Fed 5-Year expected inflation rate (\%)

83 Cleveland Fed 7-Year expected inflation rate (\%)

84 Cleveland Fed 10-Year expected inflation rate (\%)

85 Cleveland Fed 20-Year expected inflation rate (\%)

86 Cleveland Fed 30-Year expected inflation rate (\%)

87 University of Michigan 1-year-ahead inflation expectations, median

88 University of Michigan 1-year-ahead inflation expectations, variance

89 University of Michigan 5- to 10-year-ahead inflation expectations, median

90 University of Michigan 5- to 10-year-ahead inflation expectations, variance

\section{Surveys}

91 ISM: Manufacturing Prices Index (NSA, 50+ = Economic expansion)

92 ISM: Nonmanufacturing Prices Index (SA, 50+ = Economic expansion)

93 Philly Fed Business Outlook Survey: Future Prices Paid Diffusion Index (SA, \%Balance)

94 NFIB: Percent planning to raise average selling prices, net (SA, \%)

95 NFIB: Percent planning to raise worker compensation, net (SA, \%)

96 1-Year-Ahead Expected change in unemployment rate, net response

\section{Foreign prices}

97 U.S. Import Price Index: All imports (NSA, $2000=100)$

98 U.S. Import Price Index: Nonpetroleum imports (NSA, $2000=100)$

99 Euroarea 11-18: HICP: Total (SA, $2005=100)$

100 Canada: Consumer Price Index (NSA, $2010=100)$

101 Mexico: Consumer Price Index (NSA, $2010=100$ )

102 Japan: CPI: All items including imputed rent (NSA, $2010=100$ )

103 Developing Asia: Consumer prices (2005 = 100, NSA)

104 Western Hemisphere: Consumer prices $(2005=100, N S A)$
Transformation

Source

DLN

FRB/H

DLN

FRB

DLV

FRBSTL

DLV

FRBCHI

LVL

FRB

LVL

FRB

LVL

FRB

LVL

FRB

LVL

FRB

LVL

FRBCLE

LVL

FRBCLE

LVL

FRBCLE

LVL

FRBCLE

LVL

FRBCLE

LVL

FRBCLE

LVL

FRBCLE

LVL

FRBCLE

LVL

TR/UMICH

LVL

TR/UMICH

LVL

TR/UMICH

LVL

TR/UMICH

DLN

ISM

DLN

ISM

DLN

FRBPHIL

DLV

NFIB

DLV

NFIB

LVL

TR/UMICH

DLN

BLS

DLN

BLS

DLN

EUROSTAT

DLN

OECD

DLN

OECD

DLN

OECD

DLN

IMF

DLN

IMF 


\section{APPENDIX, cont'd}

\section{Nomenclature: By transformation}

DLN: Change in logs

DLV: Change in levels

LVL: Levels

\section{Nomenclature: By data source}

AC: Authors' calculation

BEA: Bureau of Economic Analysis

BLS: Bureau of Labor Statistics

CENSUS: U.S. Census Bureau

CRB: Commodity Research Bureau

CORE: CoreLogic

EIA: U.S. Energy Information Administration

EUROSTAT: Eurostat

FHFA: Federal Housing Finance Agency

FHLMC: Federal Home Loan Mortgage Corporation

FRB: Board of Governors of the Federal Reserve System

FRBATL: Federal Reserve Bank of Atlanta

FRBCHI: Federal Reserve Bank of Chicago

FRBCLE: Federal Reserve Bank of Cleveland

FRBDAL: Federal Reserve Bank of Dallas

FRBPHIL: Federal Reserve Bank of Philadelphia

FRBSTL: Federal Reserve Bank of St. Louis

GSA: Green Street Advisors

$\mathrm{H}$ : Haver Analytics

IMF: International Monetary Fund

ISM: Institute for Supply Management

NFIB: National Federation of Independent Business

OECD: Organisation for Economic Co-operation and Development

S\&P: Standard \& Poor's

TR: Thomson Reuters

TREASURY: U.S. Department of the Treasury

UMICH: University of Michigan Survey Research Center

WSJ: Wall Street Journal

NOTE: CPI, consumer price index; CPI-U, Consumer Price Index for All Urban Consumers; DOE, U.S. Department of Energy; HICP, Harmonised Index of Consumer Prices; KR-CRB, Knight-Ridder Commodity Research Bureau; MMBTU, 1 million British thermal units; MZM, money zero maturity; NSA, not seasonally adjusted; p.a., per annum; PCE, adjusted personal consumption expenditure chain-weighted price index; $\mathrm{PPI}$, producer price index; SA, seasonally adjusted; TIPS, Treasury inflation-protected securities; WTI, West Texas Intermediate. 


\section{NOTES}

1 Technically, the NKPC posits that the current-period's inflation rate depends on the next-period's inflation rate and the aggregate real marginal cost of firms in the economy. It is further assumed that aggregate real marginal cost is proportional to the difference between actual and potential output; see Rudd and Whelan (2007). Mavroeidis, Plagborg-Møller, and Stock (2014) highlight the numerous limitations of the NKPC based on the various measures of inflation expectations.

2 In April 2014, the Board of Governors released the model code and datasets for the staff's workhorse forecasting model, FRB/US. An interested analyst with access to the software required to run FRB/US can now, in principle, generate forecasts from large, structural macroeconometric models; see "FRB/US: About" (http://www.federalreserve.gov/econresdata/frbus/us-models-about.htm).

3 See Yellen (2014).

4 Greenbook forecasts can be found at http://www.federalreserve.gov/monetarypolicy/fomc_historical.htm.

5 A nowcast, sometimes called a tracking forecast, uses a variety of incoming data flows during a quarter to estimate that quarter's inflation rate; see Giannone, Reichlin, and Small (2008).

6 A direct forecast relates the period- $t$ data directly to the $h$-period-ahead data. The indirect forecast models a oneperiod-ahead relationship and propagates that forward, treating the shorter-horizon data as given.

7 See Gavin and Kliesen (2008).

8 See Stock and Watson (1999); Bernanke and Boivin (2003); Bernanke, Boivin, and Eliasz (2005); and Giannone, Reichlin, and Sala (2005). Stock and Watson have instead focused on forecasting.

9 See Smets and Wouters (2007).

10 See Gavin and Kliesen (2008) for a discussion on this point.

${ }^{11}$ See the August 16, 2013, survey report published by the Philadelphia Fed (http://www.phil.frb.org/research-and-data/real-time-center/survey-of-professional-forecasters/2013/survq313.cfm).

12 See McConnell and Perez-Quiros (2000).

${ }^{13}$ For more information about the estimation, contact the authors.

${ }^{14}$ Recall that the RMSE results in Table 4 suggested that the best-performing models were the FAVAR(1) and FAVAR(6) for CPI inflation for the post-1983 period.

15 Greenspan (2004) provides a fuller discussion in the context of a Bayesian-type model.

${ }^{16}$ Note that the chart plots smoothed probabilities, which are six-month moving averages. Thus, for March 2012, these are the average probabilities for the six months ending in March 2012.

${ }^{17}$ In quarterly terms, at an annual rate, PCEPI inflation fell from 1.3 percent in 2012:Q2 to 1 percent in 2013:Q1.

${ }^{18}$ The FOMC's projections are published quarterly and are termed the Summary of Economic Projections. See http://www.federalreserve.gov/monetarypolicy/fomcprojtabl20140618.htm.

${ }^{19}$ Converting our monthly forecasts into quarterly forecasts also reveals an expected 1.8 percent increase in the PCEPI from 2013:Q4 to 2014:Q4.

20 See "Minutes of the Federal Open Market Committee, December 17-18, 2013" (http://www.federalreserve.gov/monetarypolicy/fomcminutes20131218.htm). 


\section{Jackson, Kliesen, Owyang}

\section{REFERENCES}

Aruoba, S. Borağan and Diebold, Francis X. “Real-Time Macroeconomic Monitoring: Real Activity, Inflation, and Interactions." American Economic Review: Papers and Proceedings, May 2010, 100(2), pp. 20-24.

Atkeson, Andrew and Ohanian, Lee E. "Are Phillips Curves Useful for Forecasting Inflation?" Federal Reserve Bank of Minneapolis Quarterly Review, Winter 2001, 25(1), pp. 2-11; https://www.minneapolisfed.org/research/qr/qr2511.pdf.

Bernanke, Ben S. and Boivin, Jean. "Monetary Policy in a Data-Rich Environment." Journal of Monetary Economics, April 2003, 50(3), pp. 525-46.

Bernanke, Ben S.; Boivin, Jean and Eliasz, Piotr. "Measuring Monetary Policy: A Factor-Augmented Vector Autoregressive (FAVAR) Approach." Quarterly Journal of Economics, February 2005, 120(1), pp. 387-422.

Board of Governors of the Federal Reserve System. "Why Does the Federal Reserve Aim for 2 Percent Inflation Over Time?" Current FAQs, September 26, 2013; http://www.federalreserve.gov/faqs/economy_14400.htm.

Ciccarelli, Matteo and Mojon, Benoit. "Global Inflation." Review of Economics and Statistics, August 2010, 92(3), pp. 524-35.

Faust, Jon and Wright, Jonathan H. “Forecasting Inflation," in Graham Elliott and Allan Timmermann, eds., Handbook of Economic Forecasting. Volume 2A. Amsterdam: North Holland, 2013, pp. 2-56.

Galí, Jordi and Gertler, Mark. "Inflation Dynamics: A Structural Econometric Analysis." Journal of Monetary Economics, October 1999, 44(2), pp. 195-222.

Gavin, William T. and Kliesen, Kevin L. "Forecasting Inflation and Output: Comparing Data-Rich Models with Simple Rules." Federal Reserve Bank of St. Louis Review, May/June 2008, 90(3, Part 1), pp. 175-92; http://research.stlouisfed.org/publications/review/08/05/GavinKliesen.pdf.

Giannone, Domenico; Reichlin, Lucrezia and Sala, Luca. "Monetary Policy in Real Time," in Mark Gertler and Kenneth Rogoff, eds., NBER Macroeconomics Annual 2004. Cambridge, MA: MIT Press, 2005, pp. 161-200.

Giannone, Domenico; Reichlin, Lucrezia and Small, David. "Nowcasting: The Real-Time Informational Content of Macroeconomic Data." Journal of Monetary Economics, May 2008, 55(4), pp. 665-76.

Greenspan, Alan. "Risk and Uncertainty in Monetary Policy." American Economic Review, May 2004, 94(2), pp. 33-40.

Mavroeidis, Sophocles; Plagborg-Møller, Mikkel and Stock, James H. "Empirical Evidence on Inflation Expectations and the New Keynesian Phillips Curve." Journal of Economic Literature, March 2014, 52(1), pp. 124-88.

McConnell, Margaret M. and Perez-Quiros, Gabriel. “Output Fluctuations in the United States: What Has Changed Since the Early 1980's?" American Economic Review, December 2000, 90(5), pp. 1464-76.

Neely, Christopher J. and Rapach, David E. “International Comovements in Inflation Rates and Country Characteristics." Journal of International Money and Finance, November 2011, 30(7), pp. 1471-90.

Rudd, Jeremy and Whelan, Karl. "Modeling Inflation Dynamics: A Critical Review." Journal of Money, Credit, and Banking, February 2007, 39(Suppl. s1), pp. 156-70.

Smets, Frank and Wouters, Rafael. "Shocks and Frictions in U.S. Business Cycles: A Bayesian DSG Approach." American Economic Review, June 2007, 97(3), pp. 586-606.

Stock, James H. and Watson, Mark W. “Forecasting Inflation." Journal of Monetary Economics, October 1999, 44(2), pp. 293-335.

Stock, James H. and Watson, Mark W. "Why Has Inflation Become Harder to Forecast?" Journal of Money, Credit, and Banking, February 2007, 39(Suppl. s1), pp. 3-33.

Yellen, Janet L. "Monetary Policy and the Economic Recovery." Remarks at the Economic Club of New York, April 16, 2014; http://www.federalreserve.gov/newsevents/speech/yellen20140416a.htm. 